\title{
De la ciudadanía
}

\section{universal a la(s) \\ ciudadanía(s) local(es) ${ }^{1}$}

\section{MARÍA FLORENCIA GIROLA}

florenciagirola@gmail.com - Consejo Nacional de Investigaciones Científicas y Técnicas (CONICET); Instituto de Ciencias

Antropológicas, Facultad de Filosofía y Letras, Universidad de Buenos Aires, Argentina.

Fecha de recepción: 20 de abril de 2017

Fecha de aceptación: 16 de mayo de 2017

\section{RESUMEN}

En las sociedades de la modernidad-colonialidad capitalista, occidental y eurocentrada — según la caracterización de A. Quijano-, el ciudadano se ha constituido como el sujeto político por antonomasia, una figura que participa y acciona principalmente en la esfera institucional-estatal. Sin embargo, en las metrópolis contemporáneas se vienen desarrollando formas de participación a escala local que complejizan, enriqueceny particularizan aquellos significados - normativos y universales - históricamente asociados a la ciudadanía. El objetivo de este artículo es reflexionar, desde una perspectiva etnográfica, sobre procesosdemovilizaciónquetienenlugarenlaciudad deBuenos Aires, yqueson protagonizadosporasociaciones vecinales cuyos miembros se han organizado para hacer frente a dos problemáticas urbanas específicas: la protección del patrimonio arquitectónico yla defensa del derecho a la seguridad. El escrito se nutre de un trabajo de campo realizado en el período 2012 2015 entre residentes del barrio porteño de Floresta.

PALABRASCLAVE: ciudadanía, participación, patrimonio, seguridad, Buenos Aires.

\section{ABSTRACT}

In the capitalist, western and Europe-centred modernity-coloniality societies - according to the characterization of A. Quijano-, the citizen has become the political subject par excellence, a figure that mainly participates and acts in the institutional-state sphere. However, in the contemporaneous metrópolis, local-scale participation forms have been developed, which render these normative meanings historically related to citizenship more complex. The purpose of this article is to reflect, from an ethnographic perspective, on the mobilization processes that take place in the city of Buenos Aires, and which are conducted by neighbour associations, which members have become organized to address two specific urban issues: the protection of the architectural heritage and the defence of the right to safety.This writing feeds on a field work carried out during 2012-2015 between residents of the Buenos Aires neighbourhood of Floresta.

KEYWORDS: citizenship, participation, heritage, safety, Buenos Aires.

1 Esta investigación ha sido posible gracias a nuestro desempeño como Investigadora del Consejo Nacional de Investigaciones Científicas y Técnicas (CONICET); también gracias al financiamiento proporcionado por el proyecto UBACyT para Grupos en Formación 20020120200291: "Procesos de construcción de ciudadanía y derecho a la ciudad en Buenos Aires desde una perspectiva etnográfica", Facultad de Ciencias Sociales, Universidad de Buenos Aires. Una primera versión de este artículo fue presentada como ponencia en la XI Reunión de Antropología del Mercosur (Universidad de la República, Facultad de Humanidades y Ciencias de la Educación, Montevideo, 2015) y fue escrita con Daniela Díaz Marchi. 


\section{INTRODUCCIÓN}

La noción de ciudadanía representa una categoría esencial para comprender cómo se ha organizado lo social y lo político en la modernidad. El ciudadano ha devenido el sujeto político por excelencia de las sociedades de la modernidad-colonialidad capitalista, occidental y eurocentrada, según la precisa caracterización de Aníbal Quijano (2007).Es el miembro de un Estadonación que accede a derechos y deberes definidos y garantizados jurídicamente en virtud de dicha membresía. Este individuo genérico y desmarcado de sus particularidades de origen y condiciones sociales de vida, vale decir, desvinculado de su lugar en la división social del trabajo y despojado de marcadores diferenciales de clase-etnia-sexo-género (Ciriza, 2007), seha constituido como una figura abstracta que participa principalmente en relación a la esfera institucionaly estatal (siendola realización de elecciones periódicas la representación por antonomasia de la participación ciudadana).

De raíz kantiana-contractualista y de fuerte impronta burguesa e iluminista (Acquarone \&Caleri, 2002), esta concepción de ciudadanía - quela reducea un status legal basado en un universalismo declarativo formal - ha sido revisada por los cientistas sociales en función de los cambios que atravesaron las sociedades capitalistas, tanto centrales como periféricas, en las últimas décadas del siglo XX y en los comienzos del siglo XXI. El repliegue del Estado Benefactor, la aplicación de medidas de ajuste estructural en tiempos de globalización neoliberal, la desindustrialización, la crisis del mundo del trabajo y de las instituciones de protección social (entre otras tendencias que se registraron con matices, avances, retrocesos y resistencias en contextos nacionales específicos) ahondaron la brecha existente entre los derechos declamados y su real efectivización.

Las condiciones diferenciales de acceso a derechos, las desigualdades crecientes y el desarrollo de movimientos sociales (de mujeres, pueblos originarios y diversidades sexuales) que denunciaron sus múltiples experiencias de exclusión, han desafiado los significados normativos tradicionalmente asociados a la ciudadanía, contribuyendo al declive de dicha noción en su versión universalizante (estatizante, nacional y estática) y a una des-esencialización del concepto. Estos cuestionamientos se han producido en favor de enfoques que conciben a la ciudadanía - y por ende la lucha por el acceso a derechoscomo un artefacto histórico (a la vez producto y productor de transformaciones sociales) que se construye de manera dinámica y cambiante en relación a prácticas y discursos que confieren adscripción (o membresía) a diversos colectivos. Desde esta perspectiva, la ciudadanía se conforma y ejerce a través de una participación que se desarrolla más allá del Estado, si bien en relación con el mismo, principalmente en vínculo con los grupos sociales de pertenencia: minorías étnico-culturales, diversidades socio-sexuales, organizaciones locales-comunitarias y otras (Lacarrieu \& Raggio, 1995; Arantes, 1999). 
En una línea argumentativa similar, diversos autores han señalado que las ciudades se han constituido, actualmente, como un significativo ámbito de debate contemporáneo en torno a la incesante estructuración práctica y simbólica de la ciudadanía: desde las tempranas reflexiones de Castells (1986) acerca de las metrópolis como constructos históricos en los cuales se materializan procesos de discriminación y exclusión urbana, pero también comoarena de discusión sobre los sentidos de la ciudad y los derechos de sus habitantes, hasta la más reciente noción de ciudadanía urbana, propuesta por Donzelot (2012) a partir de los procesos de gentrificación-relegación-periubanización registrados en las ciudades francesas. Según este autor, quien retoma conocidas formulaciones de $\mathrm{H}$. Lefebvre, es en torno al espacio urbano y al derecho a la ciudad que actualmente se originan y dirimen las luchas sociales por la concreción de la ciudadanía; un planteo en concordancia con Holston y Appadurai (1999), quienes ya habían argumentado en favor de la ciudad como locus estratégico y catalizador de disputas y significados relativos al ejercicio de derechos y obligaciones.

En continuidad con estos planteos conceptuales y con estos procesos sociohistóricos sucintamente comentados, el objetivo general de este artículo es reflexionar sobre procesos de constitución de ciudadanía(s) a partir dela descripción y el análisis de particulares experiencias de organización y participación colectiva que tienen lugar en la ciudad de Buenos Aires, más específicamente en el barrio porteño de Floresta, y que son protagonizadas por asociaciones locales cuyos miembros se han movilizado a raíz de dos problemáticas urbanas específicas: por un lado, la Asociación Salvar a Floresta, que desde 2009 está organizada en torno a la preservación del patrimonio arquitectónico; por otro lado, la agrupación Floresta de Pie, surgida en 2013, que se ocupa de la defensa del derecho a la seguridad barrial.

La noción de ciudadanía, cuyos significados y apropiaciones nativas resultarán centrales en el desarrollo de estas páginas, es una categoría asociada al mundo de la política y como tal ha sido objeto de atención de la denominada antropología de la política. Este campo disciplinario

se centra en el análisis de las múltiples maneras en que las problemáticas categorías que habitualmente asociamos al universo de la política, así como otras que comúnmente se les asocian (nación, político, público, etc.) o se les oponen (privado, familia, economía, religión, etc.) son conceptualizadas por actores socialmente situados (Balbi \& Boivin, 2008, p.10).

Inscripto principalmente en el seno de las discusiones de la antropología de las ciudades (también llamada antropología urbana), este trabajo explora - entre otros aspectos- los usos y sentidos que la categoría de ciudadano/a (junto con otras) adquiría para habitantes de un sector de la ciudad de Buenos Aires que se han organizado para demandar derechos asociados a lo que 
entendían por "calidad de vida urbana". Basado en un enfoque etnográfico, el escrito se nutre del trabajo de campo llevado adelante durante el período 2012-2015 entre miembros de las dos agrupaciones barriales antes mencionadas ${ }^{2}$.

\section{ACERCA DE LOS REFERENTES EMPÍRICOS DE LA INVESTIGACIÓN}

El barrio porteño de Floresta, que se sitúa en la zona oeste de la Ciudad Autónoma de Buenos Aires, cuenta con un total de 164.815 habitantes y una densidad de 130,21 hab/ha (según datos del Censo Nacional de Población, Hogares y Viviendas realizado en 2010). Aunque durante muchos años fue una localidad donde solamente existieron quintas y lagunas formadas por lluvias y arroyos, comenzó a densificarse progresivamente tras la llegada del ferrocarril a la estación La Floresta, origen del topónimo barrial (Vattuone, 2007). En este sector periférico de la aglomeración (en tanto se encuentra alejado de la centralidad y de su casco histórico), de mediana densidad poblacional y donde prevalecen las casas bajas, los edificios de vivienda de poca altura y una composición socioeconómica heterogénea, han surgido las dos organizaciones vecinales entre cuyos miembros hemos desarrollado la investigación.

Figura 1. Barrios de la ciudad de Buenos Aires

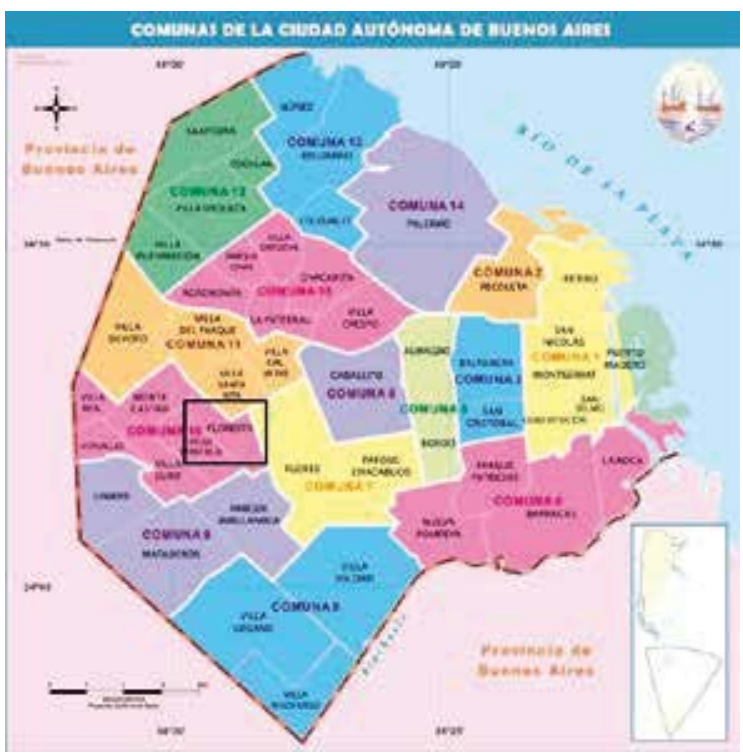

Fuente: http://mapoteca.educ.ar

2 Recurrimos a las comillas para la cita de fragmentos o términos textuales correspondientes a los interlocutores de la investigación, a quienes hemos cambiado sus nombres para preservar el anonimato. 
Figura 2. Calle del barrio de Floresta

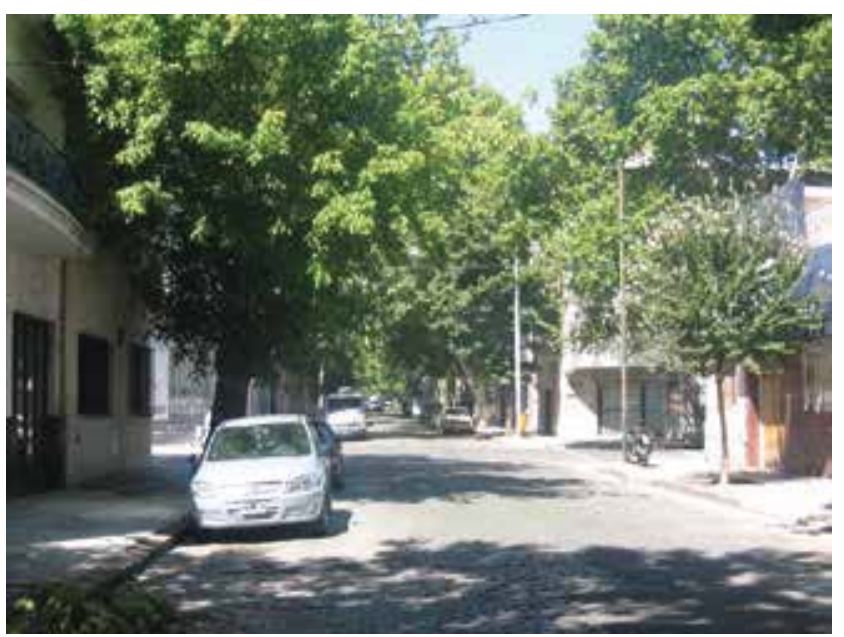

Fuente: María Florencia Girola.

sus calles adyacentes, de un polo textil de venta mayorista-minorista que atrae a particulares y a revendedores de todo el país. Este polo incluye depósitos, fábricas y talleres de confección de prendas (con mano de obra que suele vivir y trabajar en condiciones de explotación $)^{\mathbf{3}}$.

La expansión del área comercial de Floresta se realizó en detrimento de antiguas casonas del barrio (algunas de arquitectura anglo-normanday aspecto señorial), muchas de las cuales fueron reconvertidas o directamente demolidas para establecer comercios y talleres, razón por la cual la Asociación Salvar a Floresta se propuso como objetivo primordial el resguardo del patrimonio arquitectónico y la defensa del derecho de los vecinos al disfrute del mismo, metonímicamente asociado como símbolo de identidad y de un cierto "estilo de vida barrial":

3 La organización no gubernamental La Alameda estimaba - para el año 2011- la existencia de 2000 talleres textiles sin habilitación en la Ciudad de Buenos Aires, donde una gran cantidad de personas trabajan bajo la modalidad conocida como "cama caliente", ya que duermen en el lugar de trabajo, son explotados laboralmente y viven en condiciones de hacinamiento y falta de higiene (La Nación, 31/10/11). En el año 2013, otro conocido matutino informaba sobre una investigación que vinculaba a 18 marcas textiles de primeralínea con el trabajo "en condiciones insalubres" de costureros indocumentados, menores de edad inclusive, (Página 12,28/05/13). Más recientemente se produjo el allanamiento, en un domicilio del barrio de Floresta, de un taller textil clandestino donde estaban cautivos siete menores y tres adultos, todos de nacionalidad boliviana (Clarín, 04/04/17). 
Los vecinos del barrio de Floresta, cansados de la destrucción sistemática y en forma continua de nuestra identidad barrial, sintetizada en la constante demolición de nuestro patrimonio arquitectónico, el avance de las construcciones en altura como así también la implantación de fábricas y depósitos textiles de dudosa habilitación y la falta de control, fiscalización y del poder de policía por parte del Gobierno de la ciudad que permite todo esto y mucho más, hoy decimos BASTA 4 .

Salvar a Floresta se ha nutrido de la participación de hombres y mujeres con diversas ocupaciones (arquitecto, ingeniero, abogado, contadora y docente formaron parte del grupo originario), en su mayoría nacidos y criados en Floresta obien con muchos años de residencia en casas unifamiliares yen menor medida en departamentos del barrio, quienes se autorreconocían como pertenecientes a las clases medias ${ }^{\mathbf{5}}$.

Por su parte, el colectivo denominado Floresta de Pie, se gestó en 2013 como resultado de la confluencia de dos procesos simultáneos, uno de arraigo barrial y otro de mayor alcance. El primero refiere al creciente temor de algunos residentes de Floresta y alrededores (madres y docentes de escuelas, vecinos que frecuentaban la misma iglesia o que se encontraban en alguna plaza, también curas de parroquias locales) por los delitos cometidos en la zona; los cuales incluían desde la instalación de redes vinculadas al narcotráfico y la trata de personas destinadas al trabajo en talleres textiles, hasta los robos en casas de ancianos y los arrebatos a niños y adolescentes a la salida de los colegios ${ }^{6}$.

El segundo proceso remite a la realización de un Congreso sobre Trata y Crimen Organizado que tuvo lugar a principios de 2013 en la Facultad de Derecho de la Universidad de Buenos Aires, en el cual participaron referentes sociales y religiosos, militantes de agrupaciones políticas, miembros de asociaciones civiles, ONGs y otros; quienes acordaron sobre la necesidad de conformar una Red Nacional Antimafia y mapear los delitos por barrio o jurisdicción de comisaría, para hacerlos públicos y denunciarlos ante los organismos pertinentes.

En aquel encuentro se hizo presente una vecina que integraba la Asociación Civil Salvar a Floresta, alguien con un activo e intenso compromiso te-

4 Carta de presentación de la agrupación disponible en: http://www.salvarafloresta.blogspot.com.ar

5 La construcción de identidades sociales involucra un trabajo discursivo que opera a través de formas de clasificación y jerarquización que reúnen a sujetos y distinguen colectivos en base a criterios o trazos en continua producción. En tanto actos de demarcación social que se desenvuelven en un proceso dinámico, las identificaciones de actores y grupos son el resultado de dos definiciones, una externa y otra interna, vale decir, que se configuran en la confluencia del reconocimiento por otros (hetero/alter-atribución) yla auto-atribución (Penna, 1992; Vila, 1999). Para el análisis de los materiales de campo generados durante la investigación no hemos partido de definiciones precodificadas, sino que hemos priorizado las formas de auto-reconocimiento elaboradas por los interlocutores, quienes se adscribieron unánimemente a las clases medias (adjetivadas de diversos modos: "clase media-media", "clase media laburante", "clase media a la que no le sobra ni un centavo").

6 Se trata de intermitentes y fluctuantes "olas de inseguridad" que generan miedo a la ciudad y miedo en la ciudad (Giglia, 2001); temores genuinos que afectan a los vecinos en tanto están anclados en acontecimientos reales, pero que a la vez son manipulados y amplificados por los medios de comunicación. 
rritorial que ofició de enlace y permitió la convergencia de ambos procesos. A través de su iniciativa se fueron sucediendo, desde mediados de 2013, las asambleas de vecinos por la seguridad barrial reunidos en Floresta de Pie, las cuales congregaron a residentes de la jurisdicción correspondiente a la Comisaría 43 (con competencia en los barrios de Floresta, Monte Castro, Vélez Sarsfield, Villa Santa Rita y Villa Luro). Los integrantes de Floresta de Pie comenzaron a reunirse en lugares de referencia social (escuelas y parroquias) para recibir denuncias anónimas y así confeccionar el denominado "mapa del delito" de la zona, con su consiguiente ampliación, seguimiento y difusión por todos los canales posibles (blogs, redes sociales, medios audiovisuales) y con la intención de presentarlo ante las autoridades policiales locales.

A pesar de su génesis distinta y diferida en el tiempo (aunque con la participación superpuesta de algunos pocos miembros), de no poseer una condición jurídica semejante (una se ha conformado como Asociación Civil y otra no) y de abordar problemáticas diferentes (aunque no por ello desvinculadas entre sí), tanto Salvar a Floresta como Floresta de Pie se han constituido como agrupaciones autodenominadas vecinales; como organizaciones de carácter y adscripción territorial surgidas para canalizar y resolver asuntos cotidianos que preocupaban a sus miembros en tanto habitantes de una porción de la urbe (Safa Barraza y Ramírez Sáiz, 2011). Ambos colectivos han nacido del malestar generado por situaciones problemáticas -el boom comercial y la inseguridad barrial- percibidas como amenazas que atentaban contra la "calidad de vida" en este rincón de la metrópolis; y que han convocado a la organización y la participación desde la condición de vecino-ciudadano (dos categorías que, como veremos más adelante, ocultan disputas, jerarquías y desigualdades urbanas).

Con una mayoritaria presencia de adultos y adultos-mayores (repartidos proporcionalmente entre hombres y mujeres pero con escasa asistencia de jóvenes), la emergencia de Salvar a Floresta entre 2008-2009 y de Floresta de Pie en 2013 expresa la lucha de determinados sectores sociales (en su mayoría clases medias con sus complejas y variadas diferenciaciones internas) por el "derecho a tener derechos" (Arbona, 2008, p. 401). Este proceso debe indudablemente contextualizarse y comprenderse en el marco de movilizaciones más amplias que han tenido lugar en distintos barrios porteños.

Para no detenernos en una historización que excedería los límites de este artículo, basta señalar que la ciudad de Buenos Aires ha venido registrando, en los últimos años, un fortalecimiento y una mayor visibilización de acciones de raíz barrial-local, tanto en materia patrimonial como securitaria. Se trata de iniciativas que han posicionado al patrimonio y la seguridad como asuntos debatidos en la esfera pública, entendida esta última en la concepción habermasiana de un ámbito analíticamente distinguible del Estado y 
del mercado, que reúne los intereses comunes de los sujetos y que los inviste como objeto de debate (Batallán \& Campanini, 2008) ${ }^{7}$.

González Bracco (2011) ha argumentado, en el mismo sentido, que tras la superación de la aguda crisis socioeconómica que vivió el país durante el período 2001-2002 y desde la reactivación económica que siguió al período 20032004, Buenos Aires ha venido asistiendo a una proliferación de agrupaciones vecinales que, en pos de la defensa de la identidad, la historia y la memoria barrial, se oponen con vehemencia a la alteración del perfil arquitectónico de sus entornos residenciales y alertan sobre la necesidad de proteger los patrimonios urbanos frente al avance de las demoliciones, las construcciones en altura y la especulación inmobiliaria.

Por su parte, Tufró $(2007,2010)$ ha señalado que en el transcurso de la última década, la problemática del crimen y la inseguridad se han posicionado como tema insoslayable de la comunicación política y como eje de campañas electorales; al tiempo que los reclamos por una mayor seguridad se han erigido como una de las principales causas de movilización de la sociedad civil. La multiplicación de organizaciones vecinales que peticionan a las autoridades por el derecho a la seguridad en barrios tan diversos como Liniers, Paternal, Recoleta, Versalles, Villa Real, Saavedra - por nombrar sólo algunos- se ha constituido, asimismo, en concordancia con un cuasi permanente llamado a la participación por parte de los poderes públicos: desde los Consejos Barriales de Prevención del Delito y la Violencia hasta los Consejos de Prevención Comunitaria convocados por la Policía Federal a fines de los años '90 del siglo pasado; desde las asambleas del Plan Nacional de Prevención del Delito que funcionaron entre 2000-2004 hasta el Plan Nacional de Participación Comunitaria en Seguridad lanzado en abril de 2011 por el Ministerio de Seguridad de la Nación (Tufró, 2007).

En las próximas páginas interesa analizar con mayor detalle los procesos de organización y participación encarnados por Salvar a Floresta y Floresta de Pie, prestando especial atención a los argumentos y los debates puestos en juego por los integrantes de estas agrupaciones vecinales; los cuales expresaban - entre otras cuestiones - tanto concepciones sobre el orden socio-territorial como tensiones y disputas en torno a las apropiaciones legítimas e ilegítimas del espacio urbano ${ }^{8}$.

7 Desde una perspectiva comunicacional centrada en la producción social de significaciones, los trabajos de Silvia Hernández han llamado la atención sobre la creciente relevancia de organizaciones auto-denominadas vecinales que se han constituido, en las últimas décadas en la ciudad de Buenos Aires, en torno al discurso patrimonialambientalista y securitario (Hernández, 2012; 2014a; 2014b).

8 El apartado que sigue se nutre de un trabajo de campo realizado entre 2012 y 2014, el cual ha incluido: a) entrevistas grupales e individuales con integrantes de Salvar a Floresta; b) entrevistas con residentes de Floresta que adherían a los reclamos de la asociación como así también con quienes permanecían ajenos a sus demandas; c) recorridos observacionales en torno al denominado "centro histórico" de Floresta (que alberga una plaza, una iglesia y antiguas casonas) y a las principales arterias del barrio. El trabajo de campo etnográfico fue realizado junto a la Lic. Daniela Díaz Marchi. Esta producción primaria de datos (registros de observaciones y de entrevistas) fue complementada con el relevamiento y análisis de fuentes secundarias. 


\section{LA CULTURIZACIÓN DE UN CONFLICTO URBANO}

En el 2008 un puñado de habitantes de Floresta que frecuentaba su iglesia y la plaza central se sintió rápidamente identificado por una preocupación compartida:

Éramos nueve vecinos que estábamos viendo cómo Floresta perdía toda su
identidad, cómo estaba siendo atropellada por los comercios, digamos por la
industria textil en general, empezó por la avenida Avellaneda, la calle Arangu-
ren, después iba tomando toda la zona de casas, se iban poniendo talleres e iba
perdiendo el barrio la identidad que tenía (Marta, registro de entrevista grupal
con integrantes de Salvar a Floresta, marzo 2012).

Para este núcleo pionero (que pasó de la plaza al bar y finalmente a la iglesia como lugar de reunión), la conformación del centro comercial estaba modificando considerablemente la configuración socio-territorial del barrio. Según los discursos relevados, a partir del crecimiento de la Av. Avellaneda, las experiencias de los espacios públicos de Floresta pasaron a construirse principalmente en torno a la desorganización, la anomia o la des-normativización: vale decir, en torno a un desorden que asumía sentidos específicos vinculados al pasaje del "barrio tranquilo de casas" al "barrio comercial"; del "barrio familiar donde todos se conocen" al barrio del desconocimiento, el anonimato y la desconfianza; del barrio de baja-mediana densidad poblacional al hacinamiento promiscuo.

Confrontado con los recuerdos del pasado, el presente se experimentaba como una suerte de batalla perdida ante las apropiaciones con fines no-residenciales, como un avance del comercio-taller en detrimento dela casa-vecino, binomio visualizado por nuestros interlocutores como la quintaescencia de la identidad barrial: "M.: Ustedes quieren hacer una práctica (en alusión a las entrevistadoras), vayan un sábado a la tarde y hay cuadras que tienen 12 cortinas, ninguna casa, nada. Uno mira y son candado-cortina, candado-cortina, candado-cortina, hasta 13 en una cuadra; D.: No hay más vecinos, no hay más vecinos, eso es lo que yo decía antes, se perdió el barrio por eso, no hay más vecinos..." (Marta y Darío, registro de entrevista grupal con integrantes de Salvar a Floresta, marzo 2012).

En un tono similar se explayaba un residente de Floresta, quien desde su periódico local y en sintonía con esta agrupación, había contribuido a la difusión de la problemática: "el barrio más que en proceso de transformación está en proceso de destrucción, es como si lo hubiera agarrado un virus que va destruyendo todo" (Alfredo, registro de entrevista individual, noviembre 2012). La "destrucción" a la que aludía este vecino y otros entrevistados tenía múltiples manifestaciones: desde la presencia de grandes micros de larga distancia en calles estrechas, hasta las apropiaciones multitudinarias por parte de comprado- 
res mayoristas y minoristas; desde el uso de veredas por el comercio ambulante (los llamados "manteros") hasta la realización de actividades vinculadas a la privacidad del hogar (como cocinar, comer y otras necesidades fisiológicas) en calles y veredas. La exhibición de actividades del ámbito doméstico se percibía como particularmente subversiva de los códigos de urbanidad, entendidos en el sentido interaccional-goffmaniano que le asigna Giglia (2001) y que remite al conjunto de pautas que regulan los comportamientos y la presentación del yo en los espacios públicos de la ciudad.

En las vivencias de los entrevistados, la expansión del polo textil permitía el establecimiento de límites temporales entre pasado y presente, también habilitaba el trazado de fronteras socioculturales entre nosotros y otros. El crecimiento de la Av. Avellaneda había agudizado los procesos de segregación vigentes en Floresta, incrementando los conflictos derivados de la experiencia del habitar con y entre sectores económicamente desiguales y culturalmente diversos:

\begin{abstract}
Nosotros siempre decimos que hubo dos cambios en Floresta, uno es el paisaje urbano y el otro es lo que pasa de la línea municipal hacia adentro. Eso también cambió. Acá hubo una ruptura del tejido social muy grande con todo esto de la inmigración, la explotación, el trabajo esclavo, esto de la inmigración trajo una cultura que es distinta a la nuestra (Ariel, registro de entrevista individual con integrante de Salvar a Floresta, diciembre 2012).
\end{abstract}

Deudor de concepciones de cultura que la asocian a una totalidad homogénea, sobre-determinante y delimitada (concepciones cuestionadas desde la antropología, pero vigentes en los usos de sentido común), el testimonio daba cuenta de la constitución de un espacio atravesado por la segregación urbana, por tensiones entre los vecinos históricos del barrio y los recién llegados (residentes y/o usuarios entre quienes se contaban migrantes coreanos con desempeño en el rubro inmobiliario-comercial, migrantes bolivianos con trabajo como talleristas) ${ }^{9}$.

9 Aquí utilizamos la segregación en su acepción de construcción espacial delas diferencias sociales (Bernand, 1994). Su reflexiones nos han llevado a pensar que, lejos de constituirse como un término uniforme definido únicamente en virtud del convivir en la proximidad, la categoría social de "vecino" encerraba jerarquías urbanas que en este caso se expresaban a través de la antigüedad residencial y la pertenencia étnica. En este sentido, nuestra investigación se ha nutrido también de los análisis de Silvia Hernández, quien demostró que tras la aparentemente inclusiva e inocente figura del vecino se delinean modos legítimos e ilegítimos de estar en la ciudad. Como bien remarcó esta autora, su creciente uso posee un efecto de inmediatez que contribuyó a construirla como una noción ahistórica, neutra y evidente. Es tarea de los cientistas sociales sortear esta ilusión de fijeza y trasparencia, y restituir sus modalidades históricas de existencia y apropiación (Hernández, 2012). 
Figura 1: Fachadas de antiguas casas del barrio de Floresta

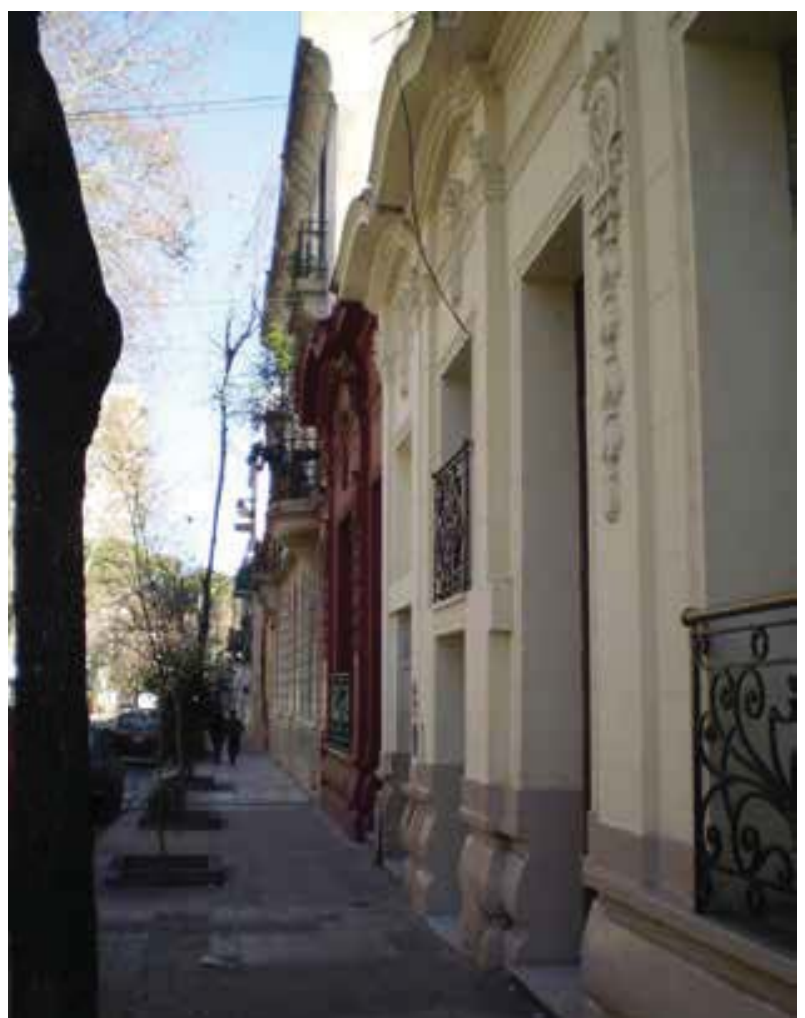

Fuente: http://www.salvarafloresta.blogspot.com.ar

Figura 2: Construcción en venta o alquiler para futuros locales comerciales

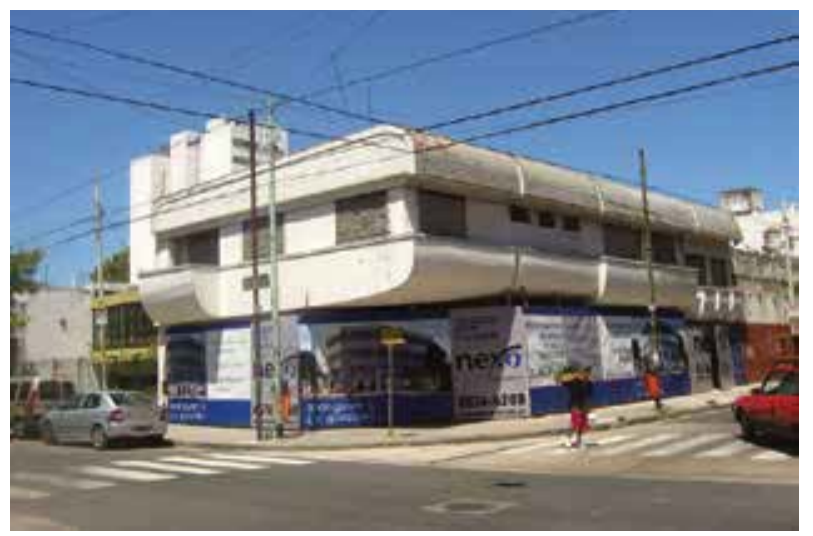

Fuente: María Florencia Girola. 
Hacia fines de 2009, tras una labor de visibilización pública de la problemática local (que incluyó marchas por la Av. Avellaneda, abrazos simbólicos de casas a punto de ser demolidas, jornadas de discusión sobre la preservación de edificios emblemáticos, presencia en medios de comunicación), este grupo de vecinos autocongregados se conformó como una asociación civil cuya meta fue la defensa de la identidad del barrio a través dela preservación de su patrimonio arquitectónico y cuyo principal interlocutor pasó a ser el gobierno porteño, destinatario central de todos los reclamos. Con un mayor marco legal para acciones realizadas en nombre de la "identidad" yel "mejoramiento del barrio", Salvar a Floresta elevó notas ante la Dirección General de Interpretación Urbanística del Gobierno de la Ciudad, firmó peticiones escritas en conjunto con otras organizaciones vecinales, presentó recursos de amparo y proyectos deley. Valiéndose del recurso de la cultura (Yúdice, 2002), las actuaciones protagonizadas por Salvar a Floresta promovieron, simultáneamente, la culturización de un conflicto urbano y la barrialización del patrimonio.

De todaslas actuaciones realizadas, una delas principales iniciativas motorizadas por salvar a Floresta ha sido, sin duda, el pedido de constitución de un Área de Protección Histórica (de ahora en adelante APH) para 19 manzanas del barrio. Regidas por la Ley 449 del año 2000, estas áreas constituyen perímetros de protección patrimonial y ambiental dentro de los cuales se privilegian las obras destinadas a uso residencial, de interés social o comunitario. Allí que se encuentra reglamentada la construcción de nuevos inmuebles; cuya altura y ocupación del suelo no pueden superar a los edificios preexistentes ya catalogados. Para los miembros de Salvar a Floresta, el barrio poseía un centro fundacional que se extendía entre las inmediaciones del ferrocarril y la Plaza Vélez Sarsfield, y que constituía un espacio digno de ser preservado por el valor histórico-patrimonial que le conferían sus características únicas: empedrado de 1911, arboleda frondosa y centenaria (con palmeras que fueron parte del antiguo Camino Real transitado por el prócer Manuel Belgrano), residencias de gran valor arquitectónico que fueron construidas en las décadas del '20 y el '30 del siglo pasado (que alimentaron la obra literaria de escritores locales como Baldomero Fernández Moreno y Roberto Arlt) y edificaciones emblemáticas (como la Parroquia Nuestra Señora de la Candelaria, la Biblioteca Pública La Floresta y el Mercado Proveedor Vélez Sarsfield).

Tratado en una audiencia que tuvo lugar a comienzos de 2010, el APHFloresta fue defendido por vecinos (integrantes y no integrantes de Salvar a Floresta) que apelaron a argumentos como los que se ponen en juego en los siguientes fragmentos: "Yo veo cómo perdemos vecinos porque se van y perdemos alumnos porque sevan, estamos perdiendo identidad, porque un barrio es eso, el barrio da identidad, arraigo, creencias, es códigos, es todo compartido (Mabel, vecina e integrante de Salvar a Floresta, Audiencia Pública, abril 2010); "hace 25 años vivo en una casa en Yerbal y San Nicolás, les aseguro que una de 
las razones que nos impide mudarnos es la perspectiva de que sea demolida, $\mathrm{o}$ sea, hoy somos nosotros los guardianes de esa casa" (Jorge, vecino de Floresta, Audiencia Pública, abril 2010). Ellenguaje emotivo-nostálgico que se hizo presente a la hora de evocar la figura próxima y reconocible del vecino, concebido como garante de la vida barrial y como custodio de los tesoros patrimoniales locales, ponía de manifiesto que no era la devaluación del valor de la propiedad o el aumento de la inseguridad y la delincuencia lo que más temían los residentes (dos argumentos esgrimidos con frecuencia por distintos colectivos vecinales en sus reclamos que si bien estaban presentes entre los miembros de Salvar a Floresta no revestían entre los de mayor peso), sino la pérdida de una modalidad de habitar la metrópolis, de una forma de convivialidad o de "estar juntos" (Donzelot, 1999), cuyo quebranto parecía encaminar a este rincón porteño hacia la disolución de los vínculos sociales:

Yo vengo a defender esta ley porque lo que quiero es saber quién vive al lado mío. Yo salía a la puerta de mi casa y me encontraba con que mi vecino era mi vecino de toda la vida, con el cual podía dialogar, y ahora salgo a la puerta de mi casa y me encuentro que al lado tengo una casa en la cual vivía una familia y están viviendo 15 o 20 personas, no sé de dónde han salido (Elba, vecina de Floresta, Audiencia Pública, abril 2010) ${ }^{\mathbf{1 0}}$. un desplazamiento de la figura del "vecino" (recortada en el ámbito barrial) hacia la figura del "ciudadano" (recortada en la esfera institucional-estatal) y un pasaje del reclamo legítimo al derecho exigible:

Queremos preservar el patrimonioyla memoria territorial, tenemos derechos como ciudadanos a pedir mediante esta ley, la protección de lo poco que nos queda para identificarnos unos a otros cada vez que nos crucemos por las calles del barrio (Carolina, vecina e integrante de Salvar a Floresta, Audiencia Pública, abril 2010).

Tenemos derechos como ciudadanos, debemos demandar mediante esta ley la protección de lo que nos queda, para seguir viviendo y disfrutando de algo que llevamos dentro de nuestros recuerdos de infancia (Leandro, vecino e integrante de Salvar a Floresta, Audiencia Pública, abril 2010).

Mediante el reclamo del APH-Floresta ante los legisladores porteños, los "vecinos" inscribían las demandas en el plano jurídico-legal y actualizaban, simultáneamente, sus derechos como ciudadanos y los deberes de los funcionarios públicos:

10 La audiencia pública a la que hacemos referencia se llevó a cabo en la Legislatura de la Ciudad Autónoma de Buenos Aires y contó con la presencia de legisladores e integrantes de la Comisión de Planeamiento Urbano de la Legislatura, del Defensor del Pueblo de la ciudad y de unos 50 vecinos del barrio. Las intervenciones que tuvieron lugar en aquella ocasión forman parte del material audiovisual disponible en Salvar a Floresta TV. 
Nosotros los vecinos, los ciudadanos, venimos con una petición entre manos hacia los legisladores que hemos elegido a través del voto libre y directo. El objetivo que nos ha traído a nosotros aquí hoy no es un objetivo económico, es másbien emotivo, genuino, quelo que estamos haciendo es tratando de rescatar valores (Norma, vecina de Floresta, Audiencia Pública, abril 2010).

Con su énfasis en el derecho a la memoria-patrimonio, a la calidad de vida urbana y a la participación en los asuntos vinculados al barrio, los vecinosciudadanos exigían el amparo de la ley y colocaban al poder local —especialmenteal Ministerio de Desarrollo Urbano dela ciudad de Buenos Aires-como responsable de la situación de abandono que aquejaba a Floresta. También reclamaban políticas de planificación respetuosas del Código de Planeamiento Urbano; que define al barrio como un sector de baja densidad poblacional.

A través del lenguaje de los derechos ciudadanos, los participantes de la audiencia pública describieron el presente de Floresta como una suerte de enfrentamiento que se libraba entre la "identidad barrial" y el "lucro/ especulación"; o bien entre "la calidad de vida" y el "tsunami inmobiliariocomercial”. Una vez más, los significados documentados a través de la investigación empírica complementan los datos provenientes de las fuentes secundarias: "acá perdemos todos porque perdemos los ciudadanos, pierde el Estado que tiene que cobrar, pierden las empresas de los servicios y gana la cadena de corrupción" (Ana Laura, registro de entrevista grupal con integrantes de Salvar a Floresta, marzo 2012). De este modo, los integrantes de la Asociación Civil vehiculizaban demandas en su doble calidad de "vecinos" y "ciudadanos respetuosos de la ley", y en oposición al "sector de intereses no vecinales" (conformado por empresarios del rubro textil e inmobiliario) que infringía las normas vigentes.

Acompañado con la firma de 700 vecinos de Floresta y barrios aledaños, el APH solicitado fue aprobado (mediante la Ley 3507) en julio de 2010, tras un trabajo de gestiones y negociaciones llevadas adelante por parte de los integrantes de Salvar a Floresta (algunos de los cuales, por profesión y desempeño laboral, poseían contactos político-legislativos). Tras la sanción de esta norma, que fue vivida como "el logro más importante" de la agrupación, ya que ponía fin a las demoliciones y la instalación de talleres textiles en un radio de 20 manzanas, el proceso de organización-participación aquí analizado continuó: los integrantes de Salvar a Floresta permanecen atentos a su falta de cumplimiento (ya que persiste el derribo de viviendas y la apertura de locales) y enfrentan las dificultades de sostener y/o extender la participación vecinal a lo largo del tiempo ${ }^{11}$.

11 En asambleas de Floresta de Pie que tuvieron lugar en 2014, cuyo análisis será desplegado a continuación, algunos participantes que conocían la luchallevada a cabo por Salvar a Floresta afirmaban, entre el disgusto yla resignación, que "el APH está destruido". 


\section{MIEDOS VECINALES, SOLUCIONES CIUDADANAS}

Los integrantes del colectivo "Floresta de Pie-Asamblea de vecinos por la seguridad barrial" comenzaron a reunirse entre fines de 2013 y principios de 2014, con una frecuencia quincena, en una iglesia del barrio de Vélez Sarsfield como lugar de encuentro 12 "Vecino" y "ciudadano" se constituyeron como las principales categorías identificatorias asumidas por los participantes de este colectivo. Vale la pena reflexionar - aunque sea brevemente - sobre la distinción de estas categorías nativas de clasificación respecto de otras de extendido uso social y académico.

Por un lado, contrariamente a nuestras presuposiciones teóricas iniciales, los integrantes de Floresta de Pie no se reconocían como "activistas", una denominación recurrente y documentada por otros investigadores para aludir a las intervenciones basadas en la gestión de demandas y el ejercicio de derechos por parte de asociaciones vecinales de clase media (Ramírez Sáiz \& Safa Barraza, 2009). El trabajo de campo y las tareas de análisis del material producido nos han llevado a revisar esta denominación - que incluso utilizáramos en un artículo anterior- y a optar por la terminología teórico-empírica de procesos de organización y participación, que estimamos mucho más congruente con los significados que los integrantes de Floresta de Pie otorgaban a sus propias prácticas. Ellos se reconocían, en efecto, no como "activistas" sino como "vecinos organizados", "vecinos que no miramos para otro lado", "vecinos que queremos generar conciencia”.

Por otro lado, la organización y participación desde el ser "vecino" procuraba diferenciarse de los procesos de movilización constituidos en torno al ser "militante" o "compañero" (categorías asociadas a la participación políticopartidaria y al partido justicialista/peronismo). En este sentido, los asistentes a las asambleas de Floresta de Pie definían a las mismas como "apartidarias", como "un espacio de vecinos independientes con derecho a peticionar". Aunque ya presente en la asociación Salvar a Floresta, la dilución de diferentes posiciones ideológicas en el lenguaje cívico de los derechos ciudadanos era más fuertemente enfatizada por los miembros de Floresta de Pie, muchos de los cuales resaltaban su no-adhesión a partidos políticos. La convocatoria a organizarse en nombre del "mejoramiento de la seguridad barrial" constituía, asimismo, un potente argumento en favor de la disolución de posibles conflictos: el "barrio" unificaba intereses y procuraba dejar en claro que la movilización no se hacía "contra ningún gobierno, ni contra el que estuvo antes, ni

12 El corpus documental de este apartado está conformado por los registros de observación de asambleas de Floresta de Pieque tuvieron lugar durante 2014 con un promedio de, aproximadamente, 15 participantes. La perspectiva de investigación adoptada ha buscado describir analíticamentelos debates delos asistentes, recuperando sus sentidos polémicos en torno al barrio, los espacios públicos, las relaciones vecinales y la seguridad/inseguridad, entre otros aspectos. Los asistentes reconocían diversas profesiones y ocupaciones: médico, cura, docente, especialista en computación, comerciante, dueño de un taller mecánico, ingeniero, instrumentadora quirúrgica, monja, ama de casa, jubilado/a. 
contra el que va a venir"; "yo quiero que nos protejan, no me importa si lo hace Macri o Cristina"13.

Retomando las reflexiones de Genestier (1999), podemos afirmar que el barrio como sistema se conformó con relación a una territorialidad fundada en su localidad, a un espacio cualificado y circunscripto por comportamientos, valores y representaciones de sus residentes; en síntesis, un universo basado en la proximidad, producido en la correspondencia entre continente y contenido. La importancia del tropo "barrio" resulta fundamental para analizar y comprender los motivos por los cuales hombres y mujeres se acercaban a las asambleas de Floresta de Pie: su participación no se fundaba en la preocupación por lo que ocurría en contextos lejanos; sino en el entorno más inmediato, donde muchos habían pasado buena parte de sus vidas y al que se sentían afectivamente vinculados.

Aun reconociendo que "te puede pasar cualquier cosa en cualquier lado", lo que movilizaba eran los delitos cometidos en la calle de la propia casa o frente a la escuela de los hijos; la alteración de la vida familiar como producto de la inseguridad; que afectaba recorridos urbanos, horarios, formas de entrar y salir de la vivienda. La cita de unos fragmentos de la carta de presentación del colectivo, confeccionada por uno de sus integrantes y la cual se leía al comenzar cada encuentro a modo de introducción frente a quienes asistían por primera vez, resulta ilustrativa en varios aspectos:

\begin{abstract}
Las asambleas de Floresta de Pie son espacios de búsqueda de soluciones a los problemas de inseguridad del barrio, siendo conscientes que detrás de cada ladrón, detrás de cada delito, hay una multiplicidad de causas. Estamos consternados por la penetración en nuestro barrio de bandas dedicadas a la trata en todas sus formas. Ya no golpean nuestras puertas en nombre de nuestros hijos y de nuestros nietos; ya entraron en nuestras casas (...). Te pedimos que no claudiques, no te rindas, no esperes a ver qué sucederá.
\end{abstract}

Esta suerte de proclama fundacional y las discusiones subsiguientes se constituían, en virtud del carácter reflexivo y performativo del lenguaje, en un ejercicio de ciudadanía, vale decir, en una práctica vinculada a la identificación de problemas colectivamente reconocidos como tales, a la formulación de demandas y a la búsqueda de posibles soluciones (Arbona, 2008). Según este autor, la discusión en torno a lo que se podría hacer no es otra cosa que la construcción activa de horizontes políticos en los que confluyen el pasado, el presente y el futuro, en este caso promovida por "ciudadanos perejiles" (según una categoría en uso en las asambleas, ya que ellos afirmaban cumplir con sus deberes, fundamentalmente el pago de impuestos, pero estaban desprotegidos en sus derechos): "nuestra idea no es organizarnos privadamente contra

13 En alusión a Mauricio Macri, por entonces Jefe de Gobierno de la Ciudad de Buenos Aires; y a Cristina Fernández de Kirchner, en aquel momento Presidenta de la Nación. 
la inseguridad, poner alarmas, cámaras, botón antipánico; si bien eso no se descarta, el objetivo central es juntarnos como ciudadanos para reclamar al Estado" (Rubén, integrante de Floresta de Pie, asamblea vecinal del 18 de septiembre de 2014).

En las reuniones autoconvocadas, los integrantes de Floresta de Pie exponían sus historias y memorias sobre el pasado barrial (una especie de "edad de oro" urbana idealizada y definitivamente perdida), frente a las cuales se contraponía un presente atravesado por el miedo al delito - cometido contra las personas y sus bienes-, por la falta de participación ("somos ciudadanos anestesiados", "una sociedad dormida") y por la desconfianza hacia el otro. Los recuerdos del barrio evocado (de casas con puertas abiertas y niños jugando en la calle) contrastaban con una actualidad de puertas cerradas que se describía a través de afirmaciones contundentes pronunciadas por mujeres, muchas de ellas de la tercera edad, quienes se sentían particularmente vulnerables por su condición genérica y etaria: "tengo miedo, tengo terror en la calle"; "yo vivo entre rejas, vivo en una cárcel” (Integrantes de Floresta de Pie, asamblea vecinal del 26 de septiembre de 2014).

La categoría analítica de barrio evocado - o practicado en el pasadodaba cuenta de una estrecha relación entre memoria y espacialidad urbana que emergía de los sentidos (de los recuerdos y olvidos) asociados a Floresta y a zonas aledañas por parte de los residentes contactados durante esta investigación. Se trata de una categoría deudora de la distinción establecida por M. de Certeau (1996) entre un espacio producido/planificado (por urbanistas, arquitectos, autoridades políticas) yun espacio consumido/practicado (porlos usuarios que se apropian cotidianamente de los lugares a través de sus múltiples "maneras dehacer"). En contraposición al barrio evocado, el barrio vivido en el presente se configuraba a través del relato de situaciones que oscilaban entre el delito yla transgresión a los códigos de urbanidad. En este sentido, los asistentes describían con detalle tanto los asaltos sufridos en la vía pública, el ingreso de delincuentes encapuchados a sus casas o los secuestros virtuales con pedido de rescate a través de llamadas telefónicas a la madrugada; como así también los usos indebidos de determinados espacios del barrio (casas tomadas, autos abandonados que se convertían en fumaderos de marihuana, veredas utilizadas para hacer asados y venta callejera).

En sus encuentros periódicos, los concurrentes a las asambleas activaban recuerdos, intercambiaban opiniones sobre el presente y proyectaban lecturas sobre el futuro (que se percibía particularmente apocalíptico para las próximas generaciones: "pobres chicos, la que les espera", "yo estoy obsesionada por ellos"); al tiempo que pensaban y delineaban posibles cursos de acción (algunos de los cuales se concretaron): desde la discusión en torno a las limitaciones del Código Contravencional de la ciudad (su eventual derogación y sustitución por otro más apropiado, no faltó quien añorará los controvertidos 
y derogados Edictos Policiales), hasta la presentación de cartas al Presidente de la Comuna 10 (a la que pertenece Floresta), solicitando la colocación de cámaras de seguridad ${ }^{14}$.

La confección del denominado Mapa del Delito a partir de las denuncias anónimas que las víctimas acercaban a integrantes de Floresta de Pie fue la principal actividad que convocó al colectivo durante el período en que realizamos trabajo de campo; un mapa que era considerado tanto un "servicio" ofrecido a los vecinos como una "herramienta de denuncia". Una primera versión presentada a fines de 2013 en la Comisaría 43 no generó respuesta policial y acrecentó la frustración de sus hacedores; sobre esta base se fueron agregando nuevos datos que culminaron en un mapeo de situaciones tan heterogéneas como: los talleres clandestinos, los prostíbulos, los puntos de venta de droga, el robo a viviendas, el robo en la vía pública y las edificaciones truchas. La nueva presentación tuvo lugar en octubre de 2014, en ocasión de un cacerolazo realizado unos pocos días después del secuestro sufrido por el padre de un niño que concurría a la escuela sede de las asambleas, y contó con una escasa presencia que fue registrada por las cámaras de una señal de $\mathrm{TV}$ y recogida por un diario de tirada nacional. Aunque decepcionados por la poca participación y repercusión mediática, dos preocupaciones constantes entre los miembros del colectivo, las asambleas de Floresta de Pie continuaron, siempre con énfasis en la seguridad barrial como uno de los principales-eincumplidos-derechos ciudadanos. Para sus participantes, la mera declamación de la ciudadanía como formalismo legal resultaba insuficiente y obligaba a su reactualización a través de la discusión asamblearia y de la conformación de sujetos activos que lucharan por el reconocimiento de sus reclamos: "nosotros como asamblea de vecinos no podemos hacer lo que corresponde al Estado, pero como vecinos podemos organizarnos y peticionar por nuestros derechos" (Claudia, Integrante de Floresta de Pie, asamblea vecinal del 23 de agosto de 2014).

La necesidad de la organización yla participación a nivel barrial se fundaba en el conocimiento local que les confería el hecho de ser vecinos ("nosotros sabemos dónde se vende la droga”) y en cierta desilusión de "la política” — a veces muy simplificadoramente asociada a la "politiquería" y a "políticos que sólo quieren embolsar"; frente a los cuales las tareas emprendidas por el colectivo eran consideradas un "trabajo de hormiga" y de "largo aliento":

14 En las asambleas presenciadas se suscitaban polémicas cuyo análisis excede el alcance de estas páginas. Los vecinos-ciudadanos no sólo discutían qué hacer y a quiénes contactar (comuneros, legisladores o medios de comunicación); también debatían sobre la condición que la policía asignaba al barrio: si lo consideraban "zona marginal-periférica" y por lo tanto descuidada o si bien se trataba de una "zona liberada" para la comisión de delitos con protección uniformada. La institución policial era en sí misma fuente de opiniones encontradas: para algunos era un recurso necesario y escaso cuyos efectivos se destinaban preferentemente a barrios de mayor poder adquisitivo; para otros era parte insoslayable del problema de la inseguridad (causante de la misma y encubridora de redes mafiosas). La palabra mafia era también analizada: para algunos era el término exacto para referirse a la situación delbarrio; otros preferían evitarla para no atemorizar a los vecinos. Lasleyes eran, por último, igualmente escudriñadas: se debatía, por ejemplo, si el problema era su inadecuación, su benignidad o su falta de aplicabilidad. 


\begin{abstract}
Ya no podemos sentarnos a esperar la ayuda de los políticos; mientras se ocupan de las elecciones, se pierden generaciones en la droga y el delito. Súmate y luchemos todos juntos por salvar el futuro de nuestros hijos. Las asambleas suman nuestro aporte de vecinos en la lucha contra el narcotráfico, el delito organizado, la corrupción (Carta de presentación de Floresta de Pie que se leía al comienzo de cada asamblea).
\end{abstract}

Decepcionados de la política partidaria, los miembros del colectivo se reconocían más ambivalentes en sus percepciones del Estado: por un lado resaltaban su burocracia e inefectividad (especialmente del aparato judicial); y por otro lado, lo consideraban el único "actor experto" y con capacidad de actuar en aras de un abordaje democrático de la problemática securitaria.

Ya sea en boca de funcionarios públicos en gestión, de políticos en tiempos de campaña electoral o de agrupaciones conformadas bajo diversos intereses, las categorías de vecino y ciudadano vienen siendo crecientemente utilizadas para aludir al habitante porteño por excelencia y al sujeto político autorizado para reclamar ante los poderes estatales. A nuestro juicio, el análisis desplegado en estas páginas (y especialmente en este segundo apartado) coincide con los sugerentes planteos de Hernández, quien ha argumentado sobre la actual vigencia de una concepción hegemónica de la categoría de vecino construida en torno a tres atributos principales: su apoliticismo, su probidad moral (los vecinos son, ante todo, "buenos" vecinos, una reserva de honestidad y buena fe), su posesión de saberes locales concretos que contrastan con los saberes abstractos e ineficaces de los políticos (Hernández, 2014b). Asimismo, la investigación ha documentado que los sentidos asociados a la categoría en uso de ciudadano se condensan ampliamente en torno a una moralización de la figura del propietario-contribuyente.

\title{
PALABRAS FINALES
}

Elinterés de conocimiento general de este artículo ha sido reflexionar sobre procesos de constitución y ejercicio de la ciudadanía que tienen lugar en la ciudad de Buenos Aires, a partir dela descripción y el análisis de particulares experiencias de organización y participación protagonizadas por dos colectivos vecinales del barrio porteño de Floresta. Lejos de conformarse como universos homogéneos y exentos de polémicas, Salvar a Floresta y Floresta de Pie han promovido iniciativas en torno a la protección del patrimonio arquitectónico y el mejoramiento de la seguridad barrial; conformándose así comoámbitos de pertenencia y membresía en los cuales - y a través de los cuales- sus participantes protestaban, reclamaban derechos ciudadanos, debatían sobre el orden y el desorden urbano, sobre los significados del barrio y los usos de sus espacios públicos, sobre las modalidades de habitar y convivir en la ciudad. 
La investigación realizada ha procurado desnaturalizar una preconstrucción de sentido común, según la cual los procesos de movilización a escala vecinal constituirán una despolitización de la figura del ciudadano. Por el contrario, aquí sostenemos que las experiencias de organización y participación de ambas agrupaciones (convocadas y sostenidas en términos del ser vecino-ser ciudadano) se constituían como auténticos procesos de ciudadanización que oscilaban — retomando los planteos de Lechner (1999) - entre la ciudadanía instrumental y la ciudadanía política activa. Mientras que la primera se dirige al sistema político institucionalizado para exigir la resolución de problemas sociales (en este caso preocupaciones ligadas a lo patrimonial-securitario que tenían anclaje en contextos urbanos concretos), la segunda expresa un desplazamiento del interés y del accionar ciudadano desde el sistema político estatal hacia la trama social y las formas de convivencia urbana. Alimentados a través de los encuentros periódicos entre residentes de Floresta y barrios aledaños, ambos colectivos expresaban un interés por la revitalización del tejido comunitario; por el fortalecimiento de espacios de conversación e intercambio basados en vínculos de confianza y cooperación entre vecinos.

A nuestro juicio, los procesos organizativo-participativos documentados complejizan algunos de los significados tradicionalmente asociados a la ciudadanía y al acceso a derechos. Por un lado, frente a concepciones clásicas que la reducen a un status legal otorgado "desde arriba" por el Estado, Salvar a Floresta y Floresta de Pie ejemplifican procesos de ciudadanización promovidos "desde abajo"; es decir, procesos de movilización mediante los cuales se procuraba efectivizar derechos y se sindicaba al Estado como no garante de los mismos y como incumplidor de sus deberes. Por otro lado, reconociéndose como los legítimos residentes-vecinos de un barrio particular aquejado por problemáticas singulares, los integrantes de ambos colectivos retaban el carácter uniforme y universalista que reviste la categoría de ciudadanía (y que ha tendido a subsumir y anular toda singularidad de los sujetos), reclamando por derechos vulnerados en virtud de dicha localización urbana.

Como bien ha señalado Arbona (2008), los procesos de ciudadanización y de lucha por los derechos que los acompañan no sólo son continuos, fluidos y dinámicos; sino que están atravesados por estructuras sociales históricamente sedimentadas y por el accionar de sujetos con específicas condiciones de clase-etnia-género. Así, mientras que en los márgenes sociales se construye ciudadanía sobre el derecho a la tierra (Pueblos Originarios) y sobre el derecho al hábitat digno (pobres urbanos); desde ciertos sectores de las clases medias se configuran procesos de ciudadanización vinculados al acceso a derechos como los aquí analizados, el derecho a la cultura-patrimonio arquitectónico y el derecho a la seguridad barrial. 


\section{REFERENCIAS}

Acquarone, A. \& Caleri, S. (2002). Ciudadanía e identidad. En La Trama de la Comunicación, 7, pp. 62-74.

Arantes, A. (1999). Desigualdad y diferencia. Cultura y ciudadanía en tiempos de globalización. En R. Bayardo y M. Lacarrieu (compiladores), La dinámica local / global. Cultura y comunicación: nuevos desafíos (pp. 23-72). Buenos Aires: Ediciones Ciccus La Crujía.

Arbona, J. M. (2008). Ciudadanía política callejera: apropiación de espacios y construcción de horizontes políticos. En Alicia Ziccardi (compiladora), Procesos de urbanización de la pobreza y nuevas formas de exclusión social: Los retos de las políticas sociales de las ciudades latinoamericanas del siglo XXI (pp. 395-416). Bogotá: CLACSO-Siglo del Hombre.

Balbi, F. \& Boivin, M. (2008). La perspectiva etnográfica en los estudios sobre política, Estado y gobierno. En Cuadernos de Antropología Social, 27, pp. 7-17.

Batallán, G. \& Campanini, S. (2008). La participación política de niñ@s y jóvenesadolescentes. Contribución al debate sobre la democratización de la escuela. En Cuadernos de Antropología Social, 28, pp. 85-106.

Bernand, C. (1994). La ségrégation dans la ville. Paris: L’Harmattan.

Castells, M. (1986). La ciudad y las masas: sociología de los movimientos sociales urbanos. Madrid: Alianza.

Ciriza, A. (2007). ¿En qué sentido se dice ciudadanía de mujeres? Sobre las paradojas de la abstracción del cuerpo real y el derecho a decidir. Guillermo Hoyos Vásquez (editor), Filosofía y teorías políticas entre la crítica yla utopía (pp.293-319). Buenos Aires: CLACSO.

DeCerteau, M.(1996). La invención delo cotidiano. 1. Artes dehacer. México DF: ITESO, Centro Francés de Estudios Mexicanos y Centroamericanos.

Donzelot, J. (1999). La nouvelle question urbaine. En Revue Esprit, 258, pp. 87-114.

Donzelot, J. (2012). ¿Hacia una ciudadanía urbana? La ciudad y la igualdad de oportunidades. Buenos Aires: Ediciones Nueva Visión.

Genestier, P. (1999). Le sortilège du quartier: quand le lieu est censé faire lien. En Les Annales de la Recherche Urbaine, 82, pp. 142-154.

Giglia, A. (2001). Sociabilidad y Megaciudades. En Estudios Sociológicos, 3, pp.799-821.

González Bracco, M. (2011). Protección del patrimonio en la ciudad de Buenos Aires: el roldelasasociacionesvecinales. En JornadasElpatrimonio urbanoyarquitectónico: la gestión para su conservación. San Miguel de Tucumán: ICOMOS/UNT.

Hernández, S. (2012). La ciudad de los vecinos: Buenos Aires, 2007-2011. En Austral Comunicación, 1(1), pp.1-15. 
Hernández, S. (2014a). Los vecinos del vecindario al protagonismo. Un aporte comunicacional para pensar los procesos urbanos. En Avatares delacomunicación y la cultura, 7, pp. 1-17.

Hernández, S. (2014b). Si te agarramos, te linchamos: los vecinos, las víctimas y la inseguridad. En Avatares de la comunicación y la cultura, 8, pp. 1-18.

Holston, J. \& Appadurai, A. (1999). Cities and Citizenship. En James Holston (comp.), Cities and Citizenship (pp.187-204). Durham: Duke University Press.

Lacarrieu, M. \&Raggio,L.(1995).Laciudadaníasimbólicaenelmarcodelaglobalización. En Cuadernos de Antropología, 16, pp. 71-101.

Lechner, N. (1999). Las condiciones sociopolíticas de la ciudadanía. En Conferencia de Clausura del IX Curso Interamericano de Elecciones y Democracia. Ciudad de México, 21 de noviembre de 1999.

Penna, M. (1992). O que faz ser nordestino. Identidades sociais, interesses e o escandalo Erundina. San Pablo: Cortez Editora.

Quijano, A. (2007). Colonialidad del poder y clasificación social. En Santiago CastroGómez y Ramón Grosfoguel (editores), El giro decolonial. Reflexiones para una diversidad epistémica más allá del capitalismo global (pp. 93-126). Bogotá: Siglo del Hombre Editores.

Ramírez Sáiz, J. M. \& Safa Barraza, P. (2009). Tendencias y retos recientes en tres metrópolis mexicanas:Ciudad deMéxico, GuadalajarayMonterrey. En Cuadernos de Antropología Social, 30, pp. 77-92.

Safa Barraza, P. \& Ramírez Sáiz, J. M. (2011). Deterioro urbano y calidad de vida en las grandes urbes: la participación de las mujeres en las organizaciones vecinales. En Revista de Estudios de Género. La ventana, 34, pp.110-145.

Tufró, M. (2007). Apoliticismo y antipoliticismo en el reclamo por seguridad. Un acercamiento discursivo-comunicacional. En Argumentos, Revista de Crítica Social, 8, pp.1-16.

Tufró, M. (2010). El cronotopo barrial. Vida cotidiana, argumentación y verdad en los discursos de una agrupación vecinal para la prevención del delito. En Signo y Pensamiento, 57, pp. 330-341.

Vattuone, J.E.(1977).Elbarrio de La Floresta. Reminiscencias de supasado. Buenos Aires: Municipalidad de la Ciudad de Buenos Aires.

Vila, P. (1999). Construcciones de identidades sociales en contextos transnacionales: el caso de la frontera entre México y Los Estados Unidos. En Revista Internacional de Ciencias Sociales, 59.

Yúdice, G. (2002). El recurso de la cultura. Usos de la cultura en la era global. Barcelona: Gedisa. 


\section{IDENTIFICACIÓN DE LA AUTORA}

María Florencia Girola es Doctora por la Universidad de Buenos Aires (UBA), Orientación Antropología. Es Profesora y Licenciada en Ciencias Antropológicas por la Facultad de Filosofía y Letras (FFyL) de la UBA e Investigadora Adjunta del Consejo Nacional de Investigaciones Científicas y Técnicas (CONICET). Docente de grado en el Departamento de Ciencias Antropológicas (FFyLUBA) y en la Carrera de Trabajo Social (Facultad de Ciencias Sociales, UBA). También ha dictado/ dicta Seminarios de Posgrado - Doctorado y Maestría - en distintas casas de estudios (FFyL-UBA; Facultad de Arquitectura, Diseño y Urbanismo-UBA y Universidad Nacional de Tres de Febrero). Se ha especializado en el campo de la antropología urbana o antropología de las ciudades, realizando investigaciones en torno a las siguientes temáticas: procesos de segregación socio-espacial; experiencias del habitar en contextos de relegación y periurbanización; iniciativas de gentrificación - renovación urbana; disputas en torno a las apropiaciones del espacio público; procesos de constitución de ciudanía y demandas vecinales (derecho a la vivienda, derecho al patrimonio material/ arquitectónico, derecho a la seguridad urbana, derecho a la calidad de vida urbana).

\section{REGISTRO BIBLIOGRÁFICO}

Girola, María Florencia (2017). De la ciudadanía universal a la(s) ciudadanía(s) local(es). InMediaciones de la Comunicación, 12(1), 155-177. 